\title{
Reactive Oxygen Species during Ischemia-Reflow Injury in Isolated Perfused Rat Liver
}

\author{
Hartmut Jaeschke, Charles V. Smith, and Jerry R. Mitchell \\ Section on Hypertension/Clinical Pharmacology, Department of Medicine, and Center for Experimental Therapeutics, \\ Baylor College of Medicine, Houston, Texas 77030
}

\begin{abstract}
The hypothesis that intracellular generation of reactive oxygen species in hepatocytes or reticuloendothelial cells may cause ischemia-reperfusion injury was tested in isolated perfused livers of male Fischer rats. GSSG was measured in perfusate, bile, and tissue as a sensitive index of oxidative stress. After a preperfusion phase of $\mathbf{3 0} \mathrm{min}$, the perfusion was stopped (global ischemia) for various times $(30,120 \mathrm{~min})$ and the liver was reperfused for another $60 \mathrm{~min}$. The bile flow $(1.48 \pm 0.17$ $\mu \mathrm{l} / \mathrm{min} \times$ gram liver weight), the biliary efflux of total glutathione (6.54 $\pm 0.94 \mathrm{nmol} \mathrm{GSH} \mathrm{eq} / \mathrm{min} \times \mathrm{g})$, and GSSG (1.59 \pm 0.23 $\mathrm{nmol}$ GSH eq/min $\times \mathrm{g}$ ) recovered to $69-86 \%$ after short-term ischemia and to 36-72\% after $2 \mathrm{~h}$ of ischemia when compared with values obtained from control livers perfused for the same period of time. During reperfusion, the sinusoidal efflux of total glutathione $(16.4 \pm 2.1 \mathrm{nmol}$ GSH $\mathrm{eq} / \mathrm{min} \times \mathrm{g})$ and GSSG $(0.13 \pm 0.05 \mathrm{nmol}$ GSH $\mathrm{eq} / \mathrm{min} \times \mathrm{g})$ did not change except for an initial 10-30-s increase during reperfusion washout. No increased GSSG secretion into bile was detectable at any time during reperfusion. The liver content of total glutathione (32.5 $\pm 3.5 \mathrm{nmol}$ GSH eq/mg protein) and GSSG (0.27 \pm 0.09 nmol GSH eq/mg protein) did not change significantly during any period of ischemia or reperfusion. We conclude, therefore, that at most only a minor amount of reactive oxygen species were generated during reperfusion. Thus, reactive oxygen species are unlikely to cause ischemia/reperfusion injury in rat liver by lipid peroxidation or tissue thiol oxidation.
\end{abstract}

\section{Introduction}

Ischemia/reperfusion-induced tissue injury is a major pathophysiological process responsible for severe organ damage in important human health problems, such as myocardial infarction, stroke, and organ transplantation (1). There is evidence that reactive oxygen species may play a role in ischemia/reperfusion injury in various organs, i.e., liver $(2-6)$, heart $(7,8)$, intestine (9), kidney (10), and brain (11). The mechanism of reactive oxygen generation through superoxide formation as proposed by McCord (12) involves the enhanced degradation of adenosine to hypoxanthine during ischemia as well as the conversion of the cytosolic enzyme xanthine dehydrogenase to xanthine oxidase (13), which uses oxygen instead of $\mathrm{NAD}^{+}$as

Address correspondence to Dr. Jaeschke, Baylor College of Medicine, Room 826E, One Baylor Plaza, Houston, TX 77030.

Received for publication 10 June 1987 and in revised form 28 September 1987.

J. Clin. Invest.

(C) The American Society for Clinical Investigation, Inc.

0021-9738/88/04/1240/07 \$2.00

Volume 81, April 1988, 1240-1246 electron acceptor. Since the oxygen concentration in tissue is extremely low during the ischemic period, the metabolism of hypoxanthine by xanthine oxidase is inhibited due to the lack of the second substrate of this reaction. Upon reflow, oxygen is available and formation of reactive oxygen species could take place, causing reperfusion injury.

However, hepatocytes and endothelial cells (14) as well as other cell types contain very effective protection mechanisms against reactive oxygen species, i.e., superoxide dismutase and glutathione peroxidase. The biliary and sinusoidal export of GSSG is a well-established and sensitive indicator of oxidative stress in vivo $(15,16)$ and in the isolated perfused rat liver $(17$, 18). If relevant amounts of reactive oxygen species were formed at any time during the reperfusion period, an increased formation of GSSG in the liver would be expected.

We therefore have measured the effects of ischemia and reperfusion on the formation and efflux of GSSG in the isolated perfused rat liver to test directly the hypothesis that reflow to previously ischemic tissue causes production of sufficient quantities of reactive oxygen species to produce structural cell damage. Although leukocyte activation may be an important factor in reflow injury, we chose a leukocyte-free system for the present study to test the hypothesis that reflow to ischemic liver causes the hepatic generation of reactive oxygen species and that these reactive intermediates are produced in sufficient quantities to kill hepatocytes. The results reported here indicate a minimal, if any, enhancement of the formation of GSSG by the liver. Thus, no evidence was found for intracellular generation of amounts of reactive oxygen species by hepatocytes or endothelial cells during global ischemia and reperfusion of the liver likely to be sufficient quantitatively to exceed cellular protective defenses against reactive oxygen injury.

\section{Methods}

Isolated perfused rat liver. Male Fischer 344 rats $(180-230 \mathrm{~g})$ were purchased from Harlan Sprague-Dawley Inc. (Houston, TX) and allowed free access to food (Wayne rodent chow) and tap water. After anesthetizing the animals with pentobarbital $(50 \mathrm{mg} / \mathrm{kg}$ i.p.) the livers were perfused as described previously $(19,20)$ with hemoglobin- and albumin-free Krebs-Henseleit bicarbonate buffer ( $\mathrm{pH} 7.4,37^{\circ} \mathrm{C}$ ) gassed with carbogen $\left(95 \% \mathrm{O}_{2}, 5 \% \mathrm{CO}_{2}\right)$. The perfusate was pumped through the livers with a peristaltic pump at a constant flow rate of $3.0-3.5 \mathrm{ml} / \mathrm{min} \times \mathrm{g}$ liver weight in a single pass mode. The bile duct was cannulated with PE 10-tubing and bile was collected in preweighed test tubes containing $4 \%$ sulfosalicylic acid in 10-min intervals. After cannulating the portal vein $(t, 0 \mathrm{~min})$, the livers were perfused for 30 min and then the perfusion was stopped. After an ischemic period (global ischemia) of 30 or $120 \mathrm{~min}$ at room temperature, the livers were perfused for another $60 \mathrm{~min}$. In additional ischemia experiments, solutions of diquat (a generous gift from Dr. Ian Wyatt of Imperial Chemical Industries, Ltd., Macclesfield, England) or $t$-butyl hydroperoxide (Sigma Chemical Co., St. Louis, MO) were infused into the 
portal vein cannula during the reperfusion period. The duration of the experiments had been $120 \mathrm{~min}$ ( $30 \mathrm{~min}$ of ischemia) or $210 \mathrm{~min}$ (120 min of ischemia) with a total perfusion period of $90 \mathrm{~min}$. Therefore, "control" experiments (without ischemia) were performed with a perfusion time of $90 \mathrm{~min}$.

The validity of the method and viability criteria of perfused rat liver have been described and discussed in detail (20-22). The viability of the livers was checked by measurement of the lactate dehydrogenase $(\mathrm{LDH})^{1}$ efflux ( $<2 \mathrm{mU} / \mathrm{min} \times \mathrm{g}$ liver weight at $30 \mathrm{~min}$ ), the lactateto-pyruvate ratio (five to six at $30 \mathrm{~min}$ ), and the bile flow.

Methods. Total soluble glutathione (GSH and GSSG) was measured in bile, perfusate, and in acidic homogenate from freeze-clamped livers by the method of Tietze (23). For the determination of GSSG a volume of bile, perfusate, or liver homogenate was mixed immediately after collection or preparation with $10 \mathrm{mM} N$-ethylmaleimide (NEM) in $100 \mathrm{mM}$ potassium phosphate buffer $(\mathrm{pH} 6.5)$ as described in detail (15). To separate GSSG from NEM and NEM-GSH adducts, an aliquot of the solution was passed through a $\mathrm{C}_{18}$-Sep-Pak cartridge (Waters Assoc., Div. of Millipore Corp., Milford, MA) followed by 1 $\mathrm{ml}$ of buffer (15). GSSG was determined in the combined eluates by the methods of Tietze (23). Hepatic ATP in the acidic homogenate of freeze-clamped liver, $\mathrm{LDH}$, lactate, and pyruvate in the perfusate were determined according to standard tests (24).

Statistics. All data are expressed as the mean \pm SD. Comparison of data sets were performed with the unpaired Student's $t$ test.

\section{Results}

When livers from male Fischer rats were perfused with KrebsHenseleit bicarbonate buffer in a single pass mode, a bile flow of $1.48 \pm 0.17 \mu \mathrm{l} / \mathrm{min} \times \mathrm{g}$ liver weight, a total biliary glutathione efflux of $6.54 \pm 0.94 \mathrm{nmol} \mathrm{GSH} \mathrm{eq} / \mathrm{min} \times \mathrm{g}$, and a GSSG efflux of $1.59 \pm 0.23 \mathrm{nmol} \mathrm{GSH} \mathrm{eq} / \mathrm{min} \times \mathrm{g}(n=5)$ were measured $30 \mathrm{~min}$ after cannulating the portal vein. The sinusoidal efflux of total glutathione at that time was $16.4 \pm 2.1 \mathrm{nmol}$ GSH eq/min $\times \mathrm{g}$ and the GSSG efflux was $0.13 \pm 0.05 \mathrm{nmol}$ $\mathrm{GSH} \mathrm{eq} / \mathrm{min} \times \mathrm{g}$. Although the efflux rates of glutathione into the perfusate remained constant over a total perfusion period of $90 \mathrm{~min}$, the biliary parameters declined gradually and were determined as $1.10 \pm 0.10 \mu \mathrm{l} / \mathrm{min} \times \mathrm{g}$ (bile flow), $3.59 \pm 0.47$ $\mathrm{nmol}$ GSH eq/min $\times \mathrm{g}$ (total glutathione efflux), and $1.11 \pm 0.25 \mathrm{nmol} \mathrm{GSH} \mathrm{eq} / \mathrm{min} \times \mathrm{g}$ (GSSG efflux) at the end of the experiment $(n=5)$.

When livers were reperfused after $30 \mathrm{~min}$ of global ischemia (Fig. 1), bile flow recovered to $\sim 95 \%$ and total glutathione efflux and GSSG efflux into bile recovered to values of $\sim 70 \%(P<0.05)$ within 30 min when compared with control livers perfused for the same period of time. No increased GSSG efflux into bile was observed. The sinusoidal efflux rates of GSH and GSSG were increased only during a short washout period and returned to control values after $30 \mathrm{~s}$ without any further change (Fig. 1). When the ischemic period was extended to $120 \mathrm{~min}$, a tremendous swelling of the liver, i.e., a $40 \%$ increase in liver weight, occurred during the first $60 \mathrm{~s}$, and continued during the first few minutes of reperfusion. Accordingly, no bile flow was detectable (Fig. 2). After 5 to $10 \mathrm{~min}$, when the liver had returned to normal size, i.e., preischemic weight, bile flow recovered to $72 \%(P<0.05)$, the biliary glutathione efflux to $55 \%(P<0.05)$, and GSSG efflux to $36 \%$ ( $P$ $<0.05$ ) of control values within $1 \mathrm{~h}$ of reperfusion. All values are compared statistically with control livers perfused for 90 min. As after short-term ischemia, no increased biliary GSSG

1. Abbreviations used in this paper: LDH, lactate dehydrogenase; NEM, $N$-ethylmaleimide.

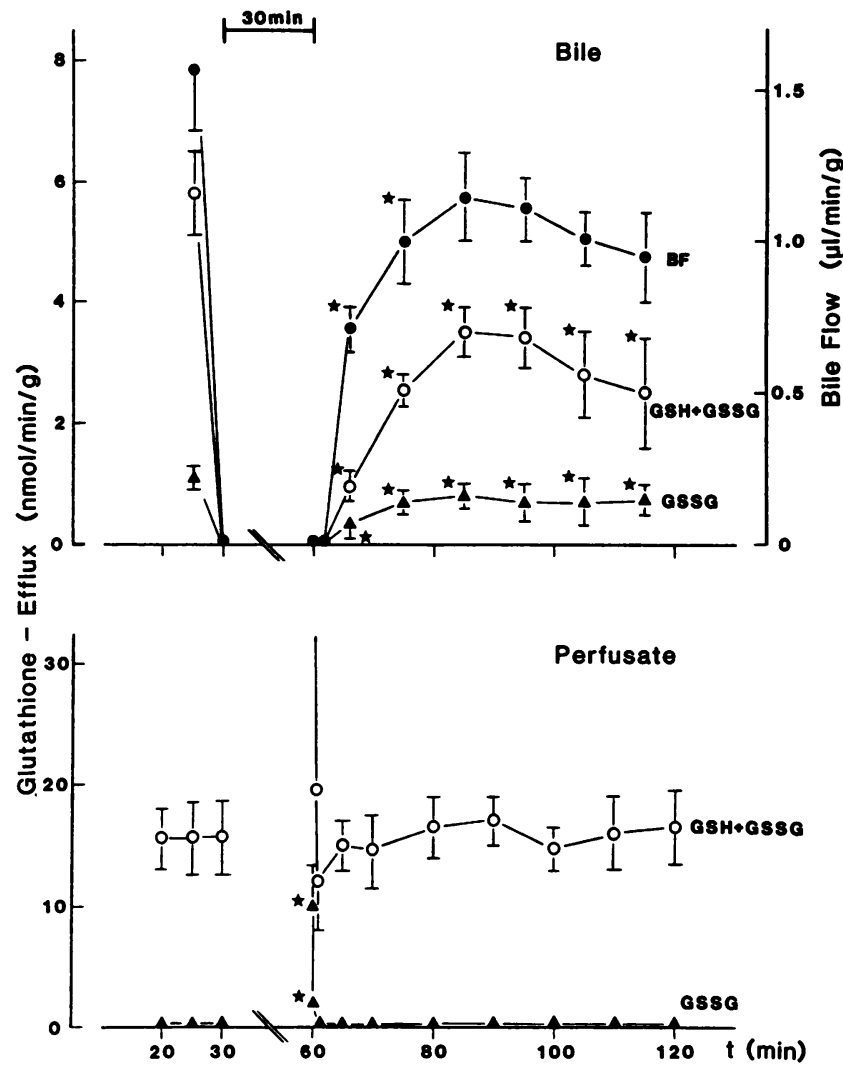

Figure 1. Bile flow and hepatic glutathione efflux after $30 \mathrm{~min}$ ischemia. Each liver was preperfused for $30 \mathrm{~min}$. After a global ischemia period of $30 \mathrm{~min}$, the livers were reperfused for another $60 \mathrm{~min}$. The total glutathione efflux (given as GSH equivalents) and the GSSG efflux (given as GSH equivalents) into bile (top) and perfusate (bottom) is shown (mean $\pm \mathrm{SD}, n=4)$. ${ }^{*} P<0.05$ compared with controls.

efflux was observed (Fig. 2). The sinusoidal efflux rates of GSH and GSSG were enhanced during the washout period (0-30 s after starting reperfusion). Although the GSSG efflux declined rapidly and returned to control values as after 30-min ischemia, the GSH efflux stayed increased for several minutes and then gradually returned to control efflux rates (Fig. 2).

The LDH release was similar to the GSH efflux (Fig. 3) in that LDH release after short-term ischemia was increased during the washout phase (30 s) and returned to control values within $5 \mathrm{~min}$. No significant liver cell damage (evaluated as enhanced LDH release) was observed during the $60 \mathrm{~min}$ of reperfusion. Long-term ischemia, however, caused a greater release of hepatic LDH that declined but did not return to basal values and again rose rapidly within $30 \mathrm{~min}$ of reperfusion, indicating severe cell damage at this time (Fig. 3). The close correlation between sinusoidal GSH efflux and LDH release in the early phases of reperfusion after long- and shortterm ischemia is shown in Fig. 4 in a higher resolution presentation of the initial reperfusion period. The peak efflux rates of LDH and GSH ( $2 \mathrm{~h}$ ischemia) occurred at the time of the maximum liver weight gain (40\% higher than preischemic liver weight), indicating an enhanced leakiness of cell membranes possibly due to mechanical stress. In contrast, GSSG efflux from the liver did not correlate with LDH efflux and liver weight gain (Fig. 4). The reason for the considerable uptake of water into liver cells might be due to a hyperosmolar state 


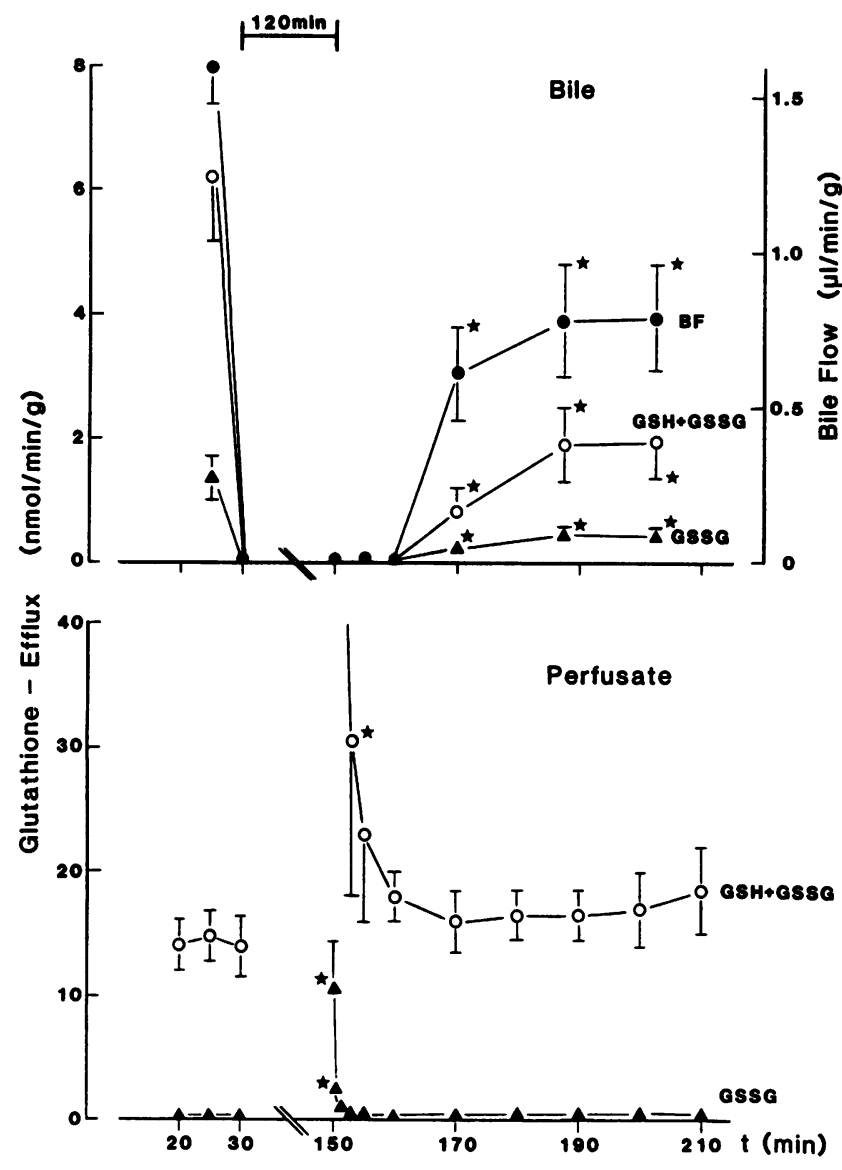

Figure 2. Bile flow and hepatic glutathione efflux after $120 \mathrm{~min}$ ischemia. Each liver was preperfused for $30 \mathrm{~min}$. After a global ischemia period of $120 \mathrm{~min}$, the livers were reperfused for another $60 \mathrm{~min}$. The total glutathione efflux (given as GSH equivalents) and the GSSG efflux (given as GSH equivalents) into bile (top) and perfusate (bottom) is shown (mean $\pm \mathrm{SD}, n=5$ ). ${ }^{*} P<0.05$ compared with controls.

secondary to the accumulation of metabolites, e.g., glucose and lactate. Indeed, during the first $10 \mathrm{~min}$ of reperfusion, the control efflux rates of glucose $(1.0-1.5 \mu \mathrm{mol} / \mathrm{min} \times \mathrm{g}$ liver weight) and lactate $(1.0-1.2 \mu \mathrm{mol} / \mathrm{min} \times \mathrm{g})$ increased dramatically. After long-term ischemia, peak values of $60-80 \mu \mathrm{mol} /$ $\min \times \mathrm{g}$ (glucose) and $10-12 \mu \mathrm{mol} / \mathrm{min} \times \mathrm{g}$ (lactate) were measured after $30 \mathrm{~s}$ with a gradual decline to control efflux rates afterwards.

There is evidence that the secretion of GSSG out of various cell types is a carrier-mediated transport that requires ATP (25-29). Because the hepatic ATP levels are significantly reduced during ischemia and do not recover totally upon reperfusion (5), the GSSG secretion of the liver might be impaired due to the lack of ATP. Therefore, we investigated the degradation and resynthesis of ATP during various ischemia/reperfusion periods. As shown in Fig. 5, the hepatic ATP content dropped exponentially to $\sim 17 \%$ of controls after $30 \mathrm{~min}$ of ischemia and to $\sim 10 \%$ of controls after $120 \mathrm{~min}$. However, after starting reperfusion the ATP content recovered rapidly and reached a new equilibrium within $15 \mathrm{~min}$, although these new ATP levels were significantly lower than the values measured before ischemia for the same livers. Tissue GSH and GSSG concentrations did not change significantly during any

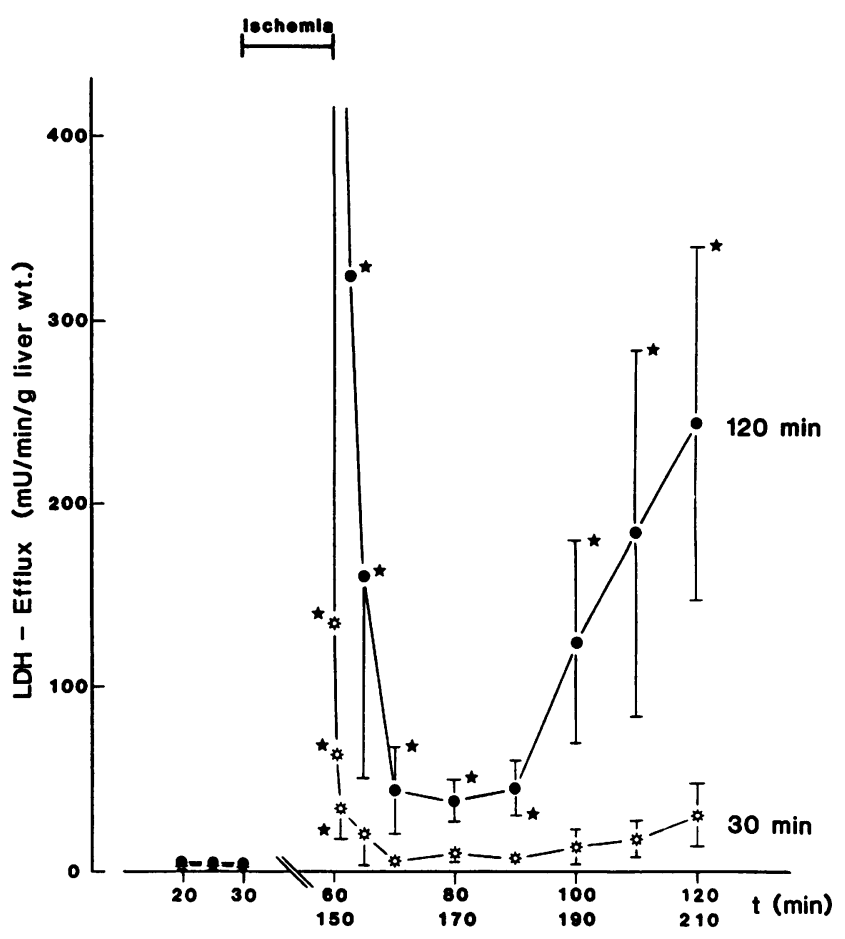

Figure 3. Hepatic LDH efflux after ischemia. LDH efflux rates were shown before the ischemic period (20-30 min) and during a 60-min reperfusion period after $30 \mathrm{~min}$ ischemia (60-120 min) or after 120 min ischemia (150-210 min). ${ }^{*} P<0.05$ compared with controls.

period of ischemia and reperfusion when compared with controls perfused for the same period of time (Fig. 6).

Because no increase in hepatic GSSG efflux into bile nor accumulation of GSSG in the liver was detectable upon reoxygenation, a solution of a superoxide-generating compound was infused to ensure that the protective mechanisms against reactive oxygen species were still operative. After $30 \mathrm{~min}$ of ischemia, the infusion of diquat into the liver to provide an intracellular oxidative stress resulted in a massive efflux of GSSG into bile and perfusate (Fig. 7). The average total efflux of GSSG from the liver during reperfusion was $18.2 \pm 3.1 \mathrm{nmol}$ GSH eq $/ \mathrm{min} \times \mathrm{g}$ liver weight. The time course of the LDH release, however, was identical to the 30-min ischemia experiments shown in Fig. 3. After $1 \mathrm{~h}$ of continuous oxidative stress in livers subjected to ischemia and reflow, LDH efflux rates of $21.3 \pm 1.8 \mathrm{mU} / \mathrm{min} \times \mathrm{g}$ were measured. Diquat infusion also caused a significant increase of the tissue GSSG content as well as a significant decrease of the hepatic GSH levels (Fig. 6). Short-term infusion of $t$-butyl hydroperoxide ( $200 \mu \mathrm{M}$ for 10 $\mathrm{min}$ ) during the reperfusion period after $30 \mathrm{~min}$ or after 120 min of ischemia resulted in total hepatic GSSG efflux rates of $33 \pm 2 \mathrm{nmol} \mathrm{GSH} \mathrm{eq} / \mathrm{min} \times \mathrm{g}$, also without affecting the LDH release significantly (data not shown). Control and previously ischemic livers responded quantitatively for $30 \mathrm{~min}$ with the same GSSG efflux rates to oxidative stress induced by diquat (Jaeschke, H., C. V. Smith, and J. R. Mitchell, unpublished observation).

\section{Discussion}

The objective of the present study was to investigate the hypothesis that intracellular generation of reactive oxygen spe- 

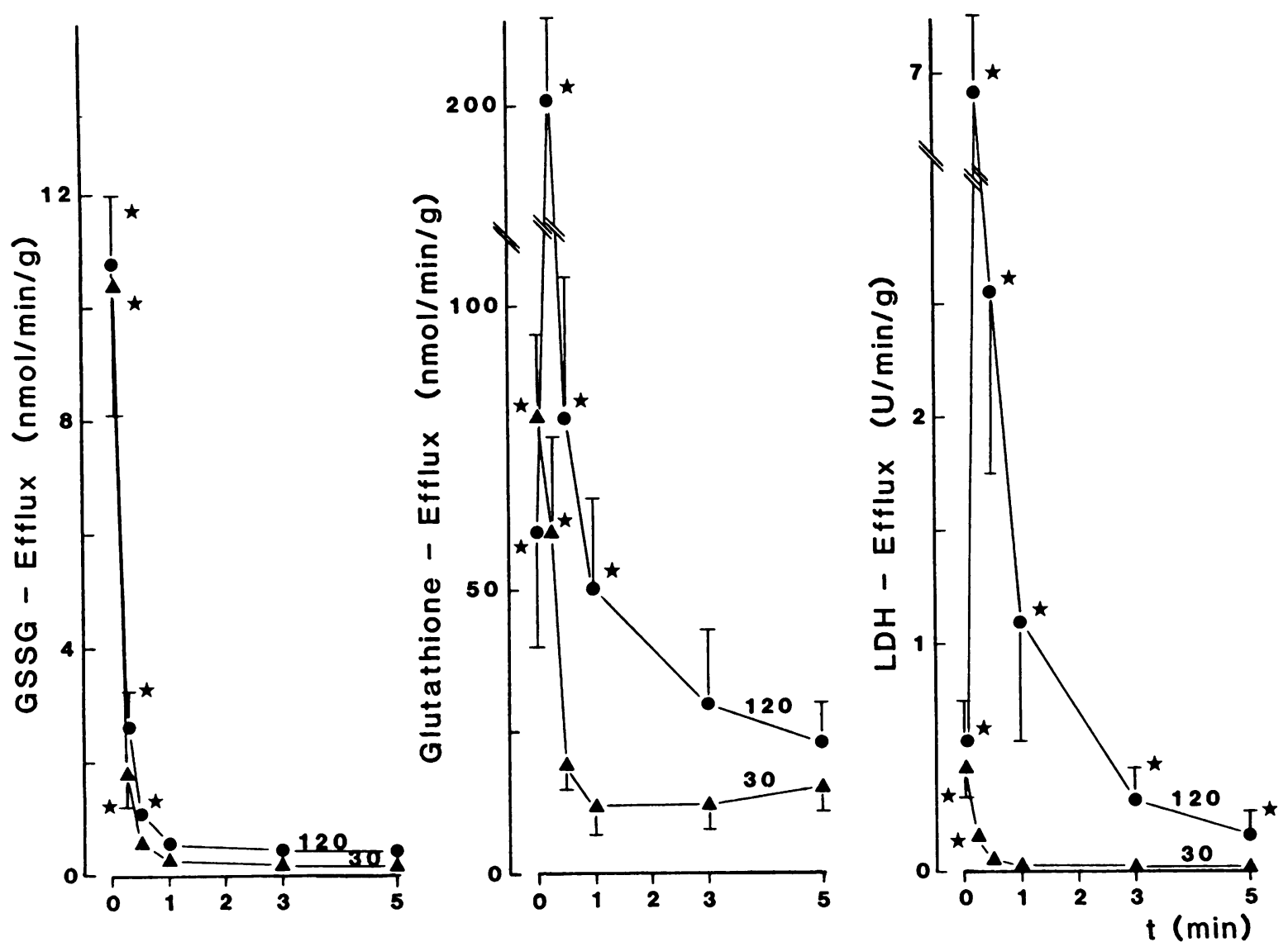

Figure 4. Sinusoidal LDH and glutathione efflux during the initial reperfusion period. The hepatic $\mathrm{LDH}$, total glutathione (given as GSH equivalents), and GSSG (given as GSH equivalents) are shown during the initial reperfusion ( $5 \mathrm{~min}$ ) after $30 \mathrm{~min}(\Delta)$ or $120 \mathrm{~min}(\bullet)$

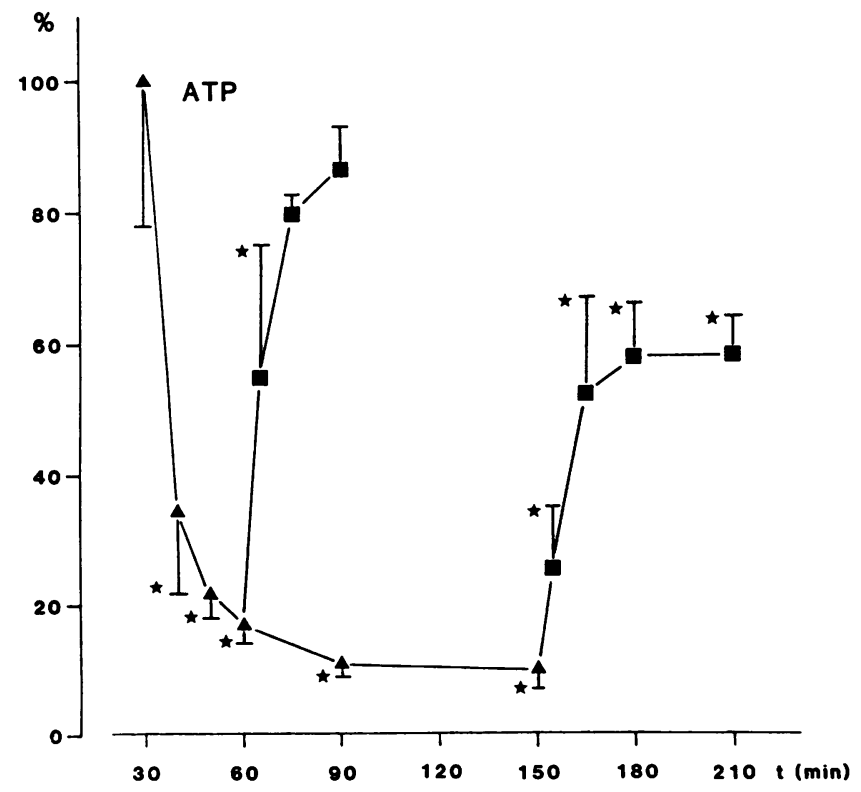

Figure 5. Hepatic ATP content during ischemia and reflow. Hepatic ATP levels were measured during an ischemic period of $120 \mathrm{~min}(\Delta)$ and during reperfusion ( $($ ) after $30 \mathrm{~min}$ of ischemia or after $120 \mathrm{~min}$ of ischemia. The ATP content is given as percent of the value measured before starting ischemia $(100 \%, 3.09 \pm 0.70 \mu \mathrm{mol}$ ATP $/ \mathrm{g}$ liver wt; $n=10$ ). Data are given as mean \pm SD of $n$ equals four to ten. ${ }^{*} P$ $<0.05$ compared with preischemic liver ATP content. ischemia. Given are the mean of $n$ equals four to five perfusions and the standard deviation, if the standard deviation is bigger than the symbol. ${ }^{*} P<0.05$ compared with controls.

cies may be responsible for ischemia-reflow injury in the liver (2-6). The major support for this theory came from experiments that showed protective effects of extracellular superoxide dismutase and catalase (3), as well as alpha tocopherol (5). The protective effect of allopurinol, a xanthine oxidase inhibitor, suggested this enzyme as the likely source of superoxide (2-4). Our approach was based on the rapid dismutation of superoxide to oxygen and hydrogen peroxide by superoxide dismutase, an enzyme that is found in high concentrations in the cytosol and in mitochondria (30). Once hydrogen peroxide is formed, glutathione peroxidase, localized in the same cellular compartment, will reduce the peroxide to water while oxidizing glutathione (GSH) to its disulfide (GSSG) (31). GSSG is reduced by glutathione reductase at the expense of NADPH. In a situation of enhanced formation of GSSG, cells actively secrete GSSG $(25,28,29)$, and this efflux has been used as a sensitive indicator of intracellular oxidative stress in vivo (15, $16)$ and in isolated perfused organs, i.e., liver $(17,18)$, heart $(27,32)$, and lungs (33). Therefore, if at any time during ischemia and reperfusion a significant formation of superoxide takes place, the enzymatic defense systems will detoxify it and will give rise to an increased GSSG formation and efflux from the liver. However, we observed very little, if any, increase in the secretion of GSSG into bile or into perfusate. Likewise, no change occurred in the intracellular GSSG content.

Nevertheless, when the hepatic glutathione defense system was challenged by infusion of a peroxide or a superoxide-generating compound, marked increase in GSSG efflux rates oc- 

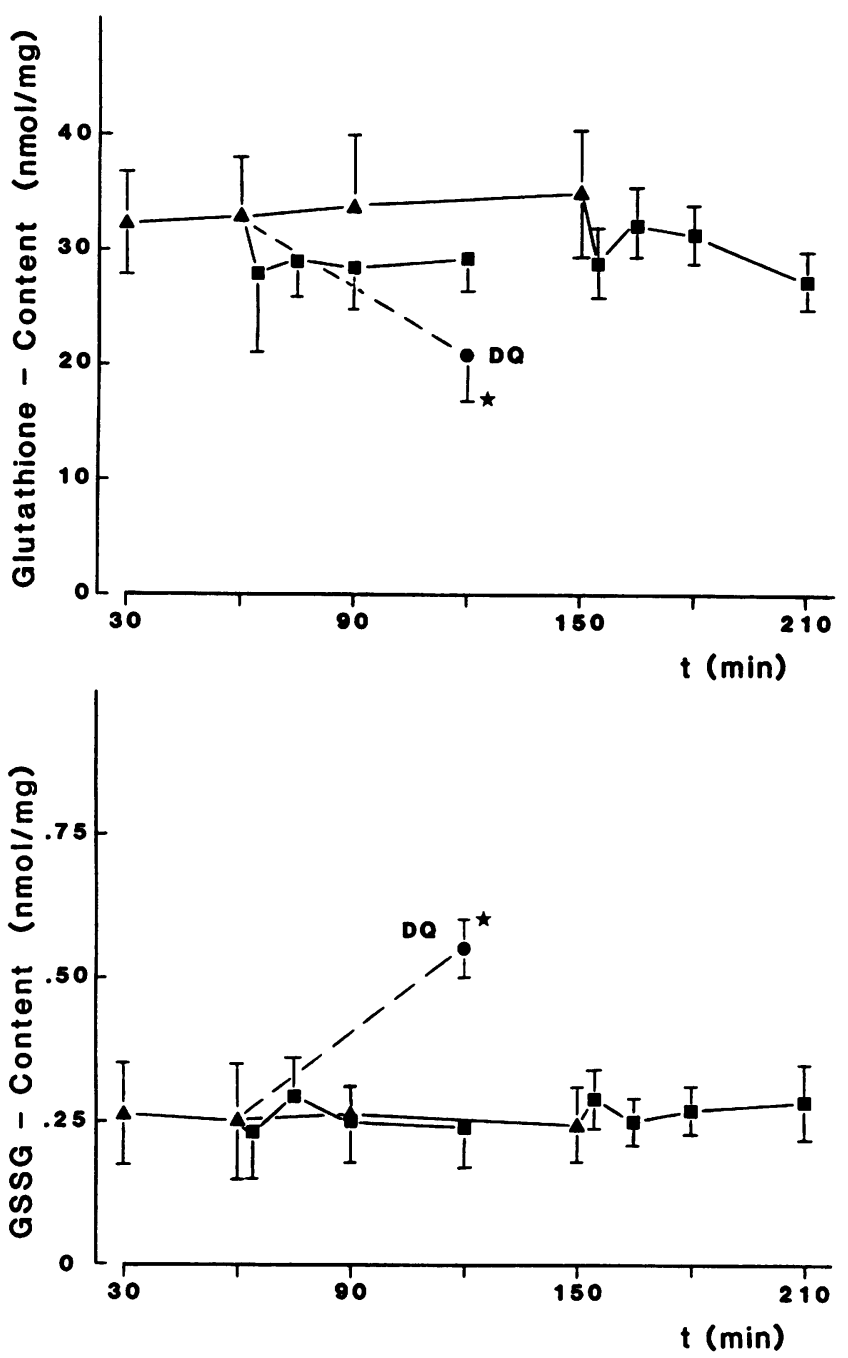

Figure 6. Hepatic GSH and GSSG content during ischemia and reflow. Hepatic levels of total glutathione (top) and GSSG (bottom) were measured during an ischemic period of $120 \mathrm{~min}(\Lambda)$ and during reperfusion ( () after 30 or $120 \mathrm{~min}$ of ischemia as well as after reflow with $200 \mu \mathrm{M}$ diquat in the perfusate $(\bullet)$ (mean $\pm \mathrm{SD}, n$ equals four to ten). ${ }^{*} P<0.05$ (reflow with vs. without diquat after $30 \mathrm{~min}$ ischemia).

curred, demonstrating a functional glutathione peroxidase and GSSG excretion system during the reperfusion period after global ischemia. Taken together, these results provide no evidence for a massive or even a moderate generation of reactive oxygen during ischemia and reperfusion of the liver.

The initial 10-30-s increase in GSSG efflux from the liver after starting reperfusion can be interpreted as washout of extracellular accumulated GSH, which oxidized spontaneously in the sinusoidal space. This view is supported by the following observations: (a) The highest GSSG concentrations in the perfusate were measured during the first few seconds, then GSSG dropped sharply and returned to control values after 20 to $30 \mathrm{~s}$ (Fig. 4); (b) Metabolites like glucose and lactate, which accumulated only to a lesser part extracellularly, showed a different efflux pattern. Lactate and glucose efflux increased during the first $20 \mathrm{~s}$ of reperfusion, had a maximum between 20 and $30 \mathrm{~s}$, and declined gradually during the first $10 \mathrm{~min}$. Thus, it is unlikely that the initial GSSG efflux represents intracellular GSSG. On the other hand an up to tenfold higher GSH efflux into the perfusate was observed during the initial period of

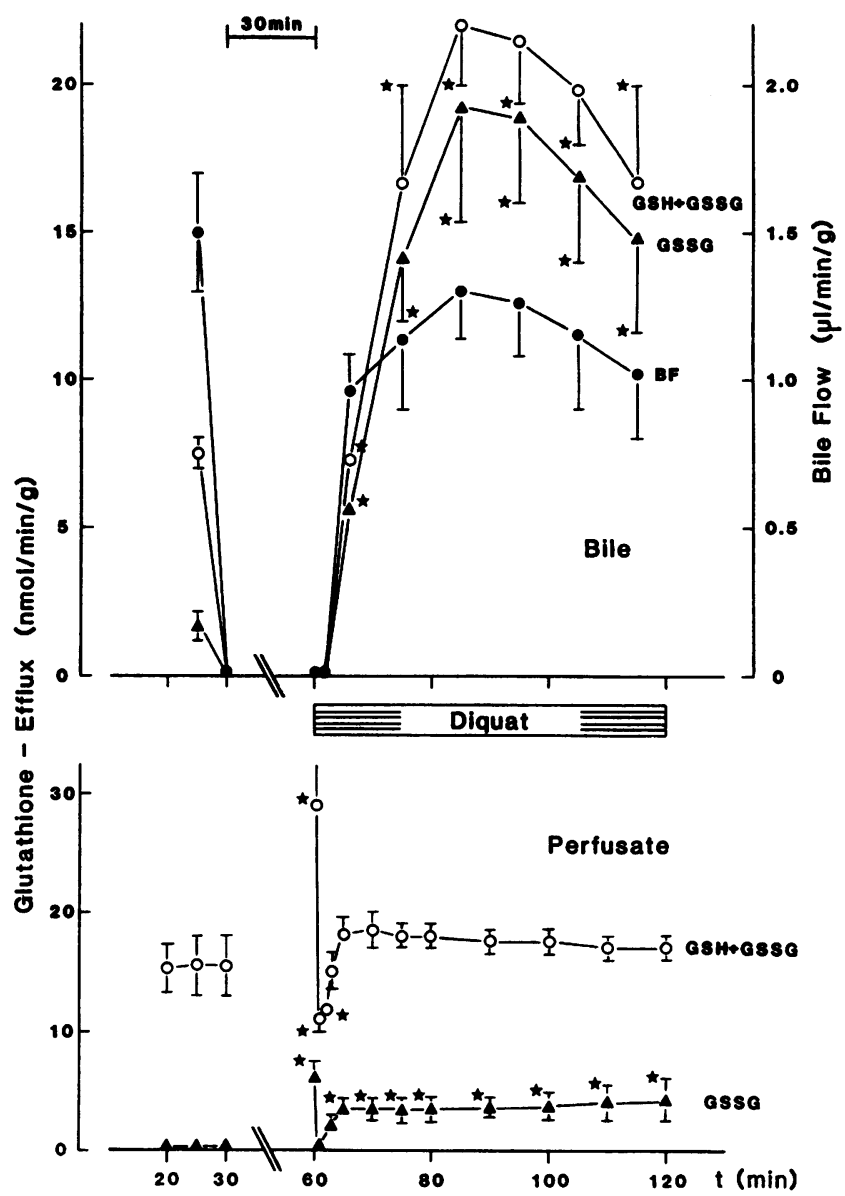

Figure 7. Bile flow and hepatic glutathione efflux after $30 \mathrm{~min}$ ischemia and diquat infusion. The livers were preperfused for $30 \mathrm{~min}$. After a global ischemic period of $30 \mathrm{~min}$, the livers were reperfused with Krebs-Henseleit bicarbonate buffer containing $200 \mu \mathrm{M}$ of diquat for another $60 \mathrm{~min}$. The total glutathione efflux (given as GSH equivalents) and the GSSG efflux (given as GSH equivalents) into bile (top) and perfusate (bottom) are shown (mean $\pm \mathrm{SD}, n=3$ ). ${ }^{*} P$ $<0.05$ compared with livers without diquat after $30 \mathrm{~min}$ ischemia (Fig. 1).

reperfusion after long-term ischemia. The enhanced GSH efflux paralleled an increased LDH efflux and the swelling of the liver, indicating a nonspecific leakage of hepatocytes, perhaps due to the mechanical stress. Since reperfusion is slower and thus liver swelling and GSH efflux is much more extended after hepatic ischemia in vivo, these findings may explain the elevated concentrations of GSH and GSSG observed in vivo in plasma but not in bile (34). Activation of leukocytes also could explain the observed increase in GSSG in the vascular compartment, but not in bile in vivo.

The toxicity of reactive oxygen species is well known (35), and leads to damage of various biomolecules (36). Lipid peroxidation in particular has been discussed as a possible mechanism of chemical-induced acute hepatotoxicity in vivo (37-42). Since reactive intermediates can alter biomolecules through multiple mechanisms, the contribution of reactive oxygen species, thiol oxidation, and lipid peroxidation to cell necrosis is difficult to evaluate. However, studies with the superoxide-producing agents diquat (41-43) and paraquat (44) and infusion of various peroxides into the isolated perfused rat 
liver $(17,45,46)$, demonstrate clearly that the rat liver is able to withstand a large amount of oxidative stress without signifcant damage (evaluated as enhanced LDH release, reduced bile flow, reduced secretion of glutathione, and increased concentration of lipid peroxidation products).

The present study confirms and extends these observations. A simulation of the oxygen radical hypothesis, i.e., the massive intracellular generation of superoxide during reperfusion of a previously ischemic liver, revealed no additional cell damage (LDH release) or impaired organ function (bile flow, GSSG secretion). An average hepatic GSSG release of $\sim 10$ $\mathrm{nmol} \mathrm{GSSG} / \mathrm{min} \times \mathrm{g}$ during diquat infusion is the consequence of $\sim 360 \mathrm{nmol} \mathrm{GSSG} / \mathrm{min} \times \mathrm{g}$ formed within the hepatocytes. These calculations are based on the $t$-butyl hydroperoxide infusion experiments: an infusion rate of 600 $\mathrm{nmol}$ peroxide/min $\times \mathrm{g}$ resulted in an efflux rate of $17 \mathrm{nmol}$ $\mathrm{GSSG} / \mathrm{min} \times \mathrm{g}(=2.8 \%)$, assuming total uptake of the peroxide into the liver (46). Thus, during the 1-h infusion period of diquat, $\sim 720 \mathrm{nmol} \times 60 \mathrm{~min}=43 \mu \mathrm{mol}$ superoxide per gram liver was generated and detoxified without damage to the liver. If one assumes that the short washout of GSSG at the beginning of the reperfusion period (Figs. 1, 2, and 4) does not represent extracellularly oxidized GSH, but actually indicates an intracellular oxidative stress, the average efflux rate of $\sim 1$ $\mathrm{nmol} \mathrm{GSSG} / \mathrm{min} \times \mathrm{g}$ during $30 \mathrm{~s}$ would then be the result of $\sim 0.036 \mu \mathrm{mol}$ superoxide per gram liver formed inside the cells. Therefore, it seems very unlikely that this small oxidative stress could produce structural damage of the liver, when a more than three orders of magnitude higher reactive oxygen formation after diquat administration (or after $t$-butyl hydroperoxide) does not affect the viability of the reperfused liver.

The significance of the present observations is not simply the lack of oxidative stress responses during ischemia-reflow injury in the isolated perfused rat liver, but the additional evidence that the methods used readily detect subtoxic oxidant stress responses. The data presented here make it highly unlikely that sufficient quantities of reactive oxygen species are generated to overwhelm endogenous defense mechanisms. Thus, the hypothesis that xanthine oxidase, located in parenchymal and in endothelial cells, causes ischemia-reflow injury in the liver by massive generation of superoxide $(2-6,12)$ is not consistent with our data. The cell damage and impaired organ function after ischemia-reflow seen in the leukocytefree isolated perfused rat liver is less severe than after the same hepatic ischemic period in vivo, where massive cell necrosis was observed $(34,47)$. This implicates an important additional unknown process in the pathogenesis of ischemia-reflow injury, perhaps involving activation of leukocytes or reticuloendothelial cells as potential sources of superoxide production.

In summary, the present study showed that global ischemia and reperfusion cause impaired organ function and cell damage (evaluated as enhanced $\mathrm{LDH}$ release) in rat liver without significant GSSG generation. We conclude, therefore, that at most a minor amount of reactive oxygen species may be generated during reperfusion. Thus, oxygen radicals are unlikely to cause ischemia/reperfusion injury in rat liver by direct structural damage through lipid peroxidation or tissue thiol oxidation.

\section{Acknowledgments}

The expert technical assistance of Ms. Marilyn L. Owens and Mr. Samuel Wyllie is gratefully appreciated.
This work was supported by National Institutes of Health grant GM-34120.

\section{References}

1. Bulkley, G. B. 1983. The role of oxygen free radicals in human disease processes. Surgery. 94:407-411.

2. Siems, W., B. Mielke, M. Mueller, C. Heumann, L. Raeder, and G. Gerber. 1983. Status of glutathione in the rat liver. Enhanced formation of oxygen radicals at low oxygen tension. Biomed. Biochim. Acta. 42:1079-1089.

3. Granger, D. N., D. Adkison, M. E. Hollwarth, J. N. Benoit, D. A. Parks, J. M. McCord, and P. R. Kvietys. 1985. Role of oxygen free radicals in ischemia-reperfusion injury in the liver. Gastroenterology. 88:1662. (Abstr.)

4. Nordstroem, G., T. Seeman, and P.-O. Hasselgren. 1985. Beneficial effect of allopurinol in liver ischemia. Surgery. 97:679-683.

5. Marubayashi, S., K. Dohi, K. Ochi, and T. Kawasaki. 1986. Role of free radicals in ischemic rat liver cell injury: prevention of damage by alpha-tocopherol administration. Surgery. 99:184-192.

6. Takekawa, S., H. Ishii, H. Takahashi, D. Ito, T. Takagi, and M. Tsuchiya. 1986. Role of free radicals in experimental ischemic hepatic injury assessed by leucocyte chemiluminescence. Hepatology. 6:1131. (Abstr.)

7. Gardner, T. J., J. R. Stewart, A. S. Casale, J. M. Downey, and D. E. Chambers. 1983. Reduction of myocardial ischemic injury with oxygen-derived free radical scavengers. Surgery. 94:423-427.

8. Chambers, D. E., D. A. Parks, G. Patterson, R. Roy, J. M. McCord, S. Yoshida, L. F. Parmley, and J. M. Downey. 1985. Xanthine oxidase as a source of free radical damage in myocardial ischemia. J. Mol. Cell Cardiol. 17:145-152.

9. Parks, D. A., and D. N. Granger. 1983. Oxygen-derived radicals and ischemia-induced tissue injury. In Oxy Radicals and Their Scavenger Systems. II. Cellular and Medical Aspects. R. A. Greenwald and G. Cohen, editors. Elsevier Science/North-Holland, New York. 135-143.

10. Paller, M. S., and R. P. Hebbel. 1986. Ethane production as a measure of lipid peroxidation after renal ischemia. Am. J. Physiol. 251:F839-F843.

11. Itoh, T., M. Kawakami, Y. Yamauchi, S. Shimizu, and M. Nakamura. 1986. Effect of allopurinol on ischemia and reperfusioninduced cerebral injury in spontaneously hypertensive rats. Stroke. 17:1284-1287.

12. McCord, J. M. 1985. Oxygen-derived free radicals in postischemic tissue injury. N. Engl. J. Med. 312:159-163.

13. Roy, R. S., and J. M. McCord. 1983. Superoxide and ischemia: conversion of xanthine dehydrogenase to xanthine oxidase. In Oxy Radicals and Their Scavenger Systems. II. Cellular and Medical Aspects. R. A. Greenwald and G. Cohen, editors. Elsevier Science/ North-Holland, New York. 145-153.

14. Suttorp, N., W. Toepfer, and L. Roka. 1986. Antioxidant defense mechanisms of endothelial cells: glutathione redox cycle versus catalase. Am. J. Physiol. 251:C671-C680.

15. Adams, J. D., B. H. Lauterburg, and J. R. Mitchell. 1983. Plasma glutathione and glutathione disulfide in the rat: regulation and response to oxidative stress. J. Pharmacol. Exp. Ther. 227:749-754.

16. Lauterburg, B. H., C. V. Smith, H. Hughes, and J. R. Mitchell. 1984. Biliary excretion of glutathione and glutathione disulfide in the rat. J. Clin. Invest. 73:124-133.

17. Sies, H., C. Gerstenecker, H. Menzel, and L. Flohe. 1972. Oxidation in the NADP system and release of GSSG from hemoglobin-free perfused rat liver during peroxidatic oxidation of glutathione by hydroperoxides. FEBS (Fed. Eur. Biochem. Soc.) Lett. 27:171-175.

18. Akerboom, T., M. Bilzer, and H. Sies. 1982. The relationship of biliary glutathione disulfide efflux and intracellular glutathione disulfide content in perfused rat liver. J. Biol. Chem. 257:4248-4252.

19. Sies, H. 1978. The use of perfusion of liver and other organs for the study of microsomal electron-transport and cytochrome P-450 systems. Methods Enzymol. 52:48-59. 
20. Krell, H., H. Jaeschke, H. Hoeke, and E. Pfaff. 1984. Bile secretion in hemoglobin-free perfused rat liver. Hoppe-Seyler's Z. Physiol. Chem. 365:1115-1122.

21. Jaeschke, H., H. Krell, and E. Pfaff. 1983. No increase of biliary permeability in ethinylestradiol-treated rats. Gastroenterology. 85:808-814.

22. Jaeschke, H., H. Krell, and E. Pfaff. 1987. Quantitative estimation of transcellular and paracellular pathways of biliary sucrose in isolated perfused rat liver. Biochem. J. 241:635-641.

23. Tietze, F. 1969. Enzymatic method for quantitative determination of nanogram amounts of total and oxidized glutathione. Anal. Biochem. 27:502-515.

24. Bergmeyer, H. U., editor. 1974. Methods of Enzymatic Analysis. Academic Press, Inc., New York. 574-579, 1446-1451, 1464-1468, 2097-2101.

25. Beutler, E. 1983. Active transport of glutathione disulfide from erythrocytes. In Functions of Glutathione: Biochemical, Physiological, Toxicological and Clinical Aspects. A. Larsson, S. Orrenius, A. Holmgren, and B. Mannervik, editors. Raven Press, New York. 65-74.

26. Akerboom, T., M. Inoue, H. Sies, R. Kinne, and I. M. Arias. 1984. Biliary transport of glutathione disulfide studied with isolated rat liver canalicular-membrane vesicles. Eur. J. Biochem. 141:211-215.

27. Ishikawa, T., and H. Sies. 1984. Cardiac transport of glutathione disulfide and S-conjugate. J. Biol. Chem. 259:3838-3843.

28. Nicotera, P., M. Moore, G. Bellomo, F. Mirabelli, and S. Orrenius. 1985. Demonstration and partial characterization of glutathione disulfide-stimulated ATPase activity in the plasma membrane fraction from rat hepatocytes. J. Biol. Chem. 260:1999-2002.

29. Ishikawa, T., M. Zimmer, and H. Sies. 1986. Energy-linked cardiac transport system for glutathione disulfide. FEBS (Fed. Eur. Biochem. Soc.) Lett. 200:128-132.

30. Fridovich, I. 1981. Superoxide radical and superoxide dismutases. In Oxygen and Living Processes. D. L. Gilbert, editor. SpringerVerlag, Heidelberg, FRG. 250-272.

31. Flohe, L. 1982. Glutathione peroxidase brought into focus. In Free Radicals in Biology. Vol. V. W. A. Pryor, editor. Academic Press, Inc., New York. 223-254.

32. Xia, Y., K. E. Hill, and R. F. Burk. 1985. Effect of selenium deficiency on hydroperoxide-induced glutathione release from the isolated rat heart. J. Nutr. 115:733-742.

33. Jenkinson, S. G., T. H. Spence, R. A. Lawrence, K. E. Hill, C. A. Duncan, and K. H. Johnson. 1987. Rat lung glutathione release: response to oxidative stress and selenium deficiency. J. Appl. Physiol. 62:55-60.

34. Jaeschke, H., C. V. Smith, H. Hughes, and J. R. Mitchell. 1987. No evidence for oxidative hepatic damage during ischemia/reflow injury. The Pharmacologist. 29:425. (Abstr.)

35. Halliwell, B., and J. M. C. Gutteridge. 1984. Oxygen toxicity, oxygen radicals, transition metals and disease. Biochem. J. 219:1-14.

36. Sies, H. 1986. Biochemistry of oxidative stress. Angew. Chem. Int. Ed. Engl. 25:1058-1071.

37. Rao, K. S., and R. O. Recknagel. 1968. Early onset of lipoperoxidation in rat liver after carbon tetrachloride administration. Exp. Mol. Pathol. 9:271-278.

38. Wendel, A., S. Feuerstein, and K. H. Konz. 1978. Acute paracetamol intoxication of starved mice leads to lipid peroxidation in vivo. Biochem. Pharmacol. 28:2051-2055.

39. Burk, R. F., R. A. Lawrence, and J. M. Lane. 1980. Liver necrosis and lipid peroxidation in the rat as the result of paraquat and diquat administration. J. Clin. Invest. 65:1024-1031.

40. Jaeschke, H., C. Kleinwaechter, and A. Wendel. 1987. The role of allyl alcohol-induced lipid peroxidation and liver cell damage in mice. Biochem. Pharmacol. 36:51-57.

41. Smith, C. V. 1987. Effect of BCNU pretreatment on diquatinduced oxidant stress and hepatotoxicity. Biochem. Biophys. Res. Commun. 144:415-421.

42. Smith, C. V. 1987. Evidence for the participation of lipid peroxidation and iron in diquat-induced hepatic necrosis in vivo. $\mathrm{Mol}$. Pharmacol. 32:417-422.

43. Smith, C. V., H. Hughes, B. H. Lauterburg, and J. R. Mitchell. 1985. Oxidant stress and hepatic necrosis in rats treated with diquat. $J$. Pharmacol. Exp. Ther. 235:172-177.

44. Brigelius, R., and M. S. Anwer. 1981. Increased biliary GSSGsecretion and loss of hepatic glutathione in isolated perfused rat liver after paraquat treatment. Res. Commun. Chem. Pathol. Pharmacol. 31:493-502.

45. Bartoli, G. M., and H. Sies. 1978. Reduced and oxidized glutathione efflux from liver. FEBS (Fed. Eur. Biochem. Soc.) Lett. 86:8991.

46. Sies, H., and K. H. Summer. 1975. Hydroperoxide-metabolizing systems in rat liver. Eur. J. Biochem. 57:503-512.

47. Mitchell, J. R., C. V. Smith, H. Hughes, M. Lenz, H. Jaeschke, L. Michael, and M. L. Entman. 1987. No evidence for reactive oxygen damage in ischemia-reflow injury. Clin. Res. 35:642A. (Abstr.) 